\title{
Unipolar mania: a necessary diagnostic concept
}

\author{
Jules Angst · Christoffel Grobler
}

Received: 20 October 2014 / Accepted: 17 January 2015 / Published online: 29 January 2015

(C) Springer-Verlag Berlin Heidelberg 2015

\begin{abstract}
In the classification of mood disorders, major depressive disorder is separate from bipolar disorders whereas mania is not. Studies on pure mania are therefore rare. Our paper reviews the evidence for distinguishing pure mania (M) and mania with mild depression (Md) from bipolar disorder. Two large epidemiological studies found a prevalence of $1.7-1.8 \%$ of $\mathrm{M} / \mathrm{Md}$ in adolescents and adults. Several clinical follow-up studies demonstrated good stability of the diagnosis after a previous history of three manic episodes. Compared to bipolar disorder, manic disorder is characterised by a weaker family history for depression, an earlier onset, fewer recurrences and better remission, and is less comorbid with anxiety disorders. In addition, mania is strongly associated with a hyperthymic temperament, manifests more psychotic symptoms and is more often treated with antipsychotics. Twin and family studies find mania to be more heritable than depression and show no significant transmission from depression to mania or from mania to depression. Cardiovascular mortality is elevated among patients with mood disorders generally and is highest among those with mania. In non-Western countries, mania and the manic episodes in bipolar disorder are reported to occur more frequently than in Western countries.
\end{abstract}

Keywords Classification - Mania - Bipolar disorder . Course $\cdot$ Cardiovascular mortality

\footnotetext{
J. Angst $(\bowtie)$

Department of Psychiatry, Psychotherapy and Psychosomatics, Psychiatric Hospital, University of Zurich, Zurich, Switzerland e-mail: jules.angst@uzh.ch

C. Grobler

Department of Psychiatry, Walter Sisulu University School

of Medicine, Port Elizabeth, South Africa
}

\section{Introduction and history of diagnostic concepts of mood disorders}

Despite long-standing debate and efforts of research and conceptualisation, unipolar mania (UM), embracing pure mania (M) and mania with mild depression $(\mathrm{Md})$, is not integrated into the latest edition of the Diagnostic and Statistical Manual of Mental Disorders-DSM-5 [1]—or the forthcoming revision of the International Classification of Diseases-ICD-11-but continues to be subsumed under bipolar disorder.

The purpose here is to summarise and to update the evidence for the existence of UM, which has been the subject of several recent major reviews of clinical, transcultural, epidemiological, genetic, biological and treatment studies [2-8].

\section{Historical development}

Mania and melancholia as phenomena were first described by the ancient Greeks; the semantic change which since then has led to the modern meanings of the terms [9-11] lies outside the scope of this brief article. The cyclical association of mania and melancholia as a distinct illness, the forerunner of the modern concept of bipolar disorder, was identified in the nineteenth century by French psychiatrists and named "folie circulaire" [12] and "folie à double forme" [13]. "Circular insanity" as a separate disorder was subsequently absorbed into Kraepelin's broad category of manic-depressive insanity (1899) [14].

In the nineteenth century, there were scientists and clinicians, however, who upheld the separateness of mania and melancholia from Falret's nosological entity. They included the influential German neurologist Carl Wernicke (18481905), for whom psychiatric disorders were brain disorders 
and mania a state of hyperfunction of nerve transmission and activity, a different disorder from its counterpart, melancholia, defined as afunction or hypofunction, even though the two disorders frequently co-occurred. Wernicke described mania as being more recurrent, with shortening intervals between episodes, and having a worse prognosis [15].

In Wernicke's lineage, Karl Kleist (1879-1960), Karl Leonhard (1904-1988) and Edda Neele (1910-2005) maintained the distinction between mania, melancholia and "circular insanity", considering the latter to be a separate disorder. In opposition to Kraepelin's all-inclusive manicdepressive psychoses, Karl Kleist originated the concept of a unipolar-bipolar dichotomy of mood disorders, which distinguished unipolar [einpolig] melancholia and UM as syndromes [16] and later as two separate diagnostic classes [17] with a certain mutual affinity (i.e. bipolarity as a combination of two unipolar conditions). Leonhard ultimately coined the current, Latin-derived, terms "unipolar" and "bipolar" [18]. A key genetic study that distinguished unipolar [einpolig] mania and melancholia from bipolar [zweipolig] disorders was published by Kleist's pupil, Neele [19], and endorsed by Kleist in his foreword.

In the 1960s, Kraepelin's dominant broad concept of manic-depressive psychoses was tested from two angles: by Angst for the heterogeneity of depression and by Perris, who hypothesised a dichotomy between unipolar depression and bipolar disorder based on Leonhard [18]. The unipolar-bipolar dichotomy, distinguishing unipolar depression from manic-depressive disorder, was confirmed and validated by the family studies of Angst [20], Perris [21] and Winokur et al. [22].

The bipolar concept was subsequently refined by Dunner, Gershon and Goodwin in 1976 [23] with the introduction of the bipolar-II diagnosis and by Akiskal in 1983 [24], who conceptualised the bipolar spectrum [bipolar and unipolar schizo-affective, bipolar-I (BP-I) disorder, bipolar-II (BPII) disorder] and unipolar depression, subclassified by the presence or absence of a family history of bipolar disorder.

But it continues to be assumed that mania is part of bipolar disorder. Were Kleist, Neele and Leonhard wrong in maintaining that mania was a separate disorder and that the common validators-genetics, course, mortality and temperament-could prove it to be so? This is not an exercise of nosological hairsplitting; ultimately, it has clinical implications for treatment.

Starting in 1978, Angst separated mania with Md from BP-I disorder (MD) and integrated this typology into a two-dimensional spectrum, one dimension being syndromal quality: M (mania), Md (mania with minor depressive disorders), MD (BP-I), Dm (BP-II), D [major depressive disorder (MDD)] and the other dimension being severity: symptoms, minor, major and psychotic syndromes [25]. Minor syndromes include hypomania (m), minor bipolar disorders (md) and minor depressive disorders (d) [26].
In a further step, temperament and personality features were integrated into a third dimension of the mood spectrum, on the basis of the work of Kretschmer [27] and of the conceptualisation of personality types by Tellenbach (melancholic type) [28, 29] and von Zerssen (manic type) [30, 31]. This three-dimensional mood spectrum [32] comprises depressive, hypomanic/hyperthymic, cyclothymic temperaments and their pathological forms (depressive, hyperthymic, cycloid, borderline PD) [33].

\section{Current evidence for a separate diagnosis of mania}

Evidence from epidemiological studies

By their very nature, prospective epidemiological studies are the most representative and convincing. In the EDSP (Early Developmental Stages of Psychopathology) study (Munich), 3,021 adolescents and young adults, aged 14-24 at baseline, were followed up three times until they were 21-34 years old [34]. A cumulative incidence rate of $2.9 \%$ for manic and $4.0 \%$ for hypomanic episodes was found. Half the subjects initially diagnosed with mania developed major depressive episodes (MDE) over the 10-year period; a further $26 \%$ developed minor depression. Nonetheless, the final prevalence rate for UM was $1.5 \%$ and for unipolar hypomania $3.6 \%$ of the general population (in both cases without MDE). Weighted, $36.9 \%$ of the subjects with BP-I had unipolar mania (M, Md), and unweighted 33 of 84 observed cases. Unipolar hypomania $(\mathrm{m} / \mathrm{md})$ was found in $1.8 \%$ ( $\mathrm{m}$ in $0.9 \%$ and minor bipolar disorder (md) in $0.9 \%$ ) [34]. Subjects with UM did not differ significantly from those with bipolar disorder in terms of clinical and course characteristics, impairment and help seeking. The same was true for comparisons between $\mathrm{M}$ and Md.

In the very large, representative US National Comorbidity Survey Adolescent Supplement (NCS-A), 10,123 adolescents aged 13-18 were investigated cross-sectionally. The lifetime prevalence of $\mathrm{M} / \mathrm{Md}$ (mania without MDE) was $1.7 \%$ and of BP-I/BP-II disorder $2.5 \%$; the past year prevalences were 1.3 and $2.2 \%$, respectively (Table 1).

The mania only group (M/Md) had an earlier onset, fewer episodes and significantly lower comorbidity with anxiety disorders than the bipolar group [35]. These recent, representative findings accord with the earlier reviews of clinical studies by Young et al. [36] and Pacheco Palha and Arrojo [37]. The latter authors also stress the excess of hyperthymic temperament and manic personality among patients with mania and their better long-term adjustment, "which leads us to believe that UM may constitute a distinct entity". 
Table 1 Diagnostic stability of unipolar mania (UM)

\begin{tabular}{|c|c|c|c|c|c|c|c|c|}
\hline Author & Country & Year & Diagnosis & Min episodes & Follow-up years & Total sample & Subsample UM & $\%$ \\
\hline \multicolumn{9}{|l|}{ Prospective } \\
\hline $\mathrm{Xu}$ and Chen & China & 1992 & DSM-III mania & $1+$ & 10 & 24 & 18 & 75.0 \\
\hline \multicolumn{9}{|l|}{ Retrospective } \\
\hline Makanjuola & Nigeria & 1982 & RDC mania & $2+$ & $1+($ median $)$ & 36 & 12 & 33.3 \\
\hline Solomon et al. & USA & 2003 & BP-I or schizo-mania & $1+$ & $15-20$ & 27 & 7 & 25.9 \\
\hline Yazici et al. & Turkey & 2008 & DSM-IV mania & $4+$ & 7 & 34 & 30 & 88.2 \\
\hline
\end{tabular}

Most significant result is in bold

DSM Diagnostic and Statistical Manual of Mental Disorders

$R D C$ Research Diagnostic Criteria

$B P-I$ bipolar-I disorder

Evidence from clinical studies

\section{Diagnostic stability of unipolar mania}

Several follow-up studies have checked the diagnostic stability of UM (Table 3). A 10-year prospective study (19811991) conducted in China by Xu and Chen [38] using the Present State Examination (PSE) found that in 18 of 24 (75\%) patients with DSM-III UM the diagnosis remained unchanged. The retrospective follow-up data in Table 3 show that the diagnostic stability increases in step with the increasing number of manic episodes: it was highest in the study of Yazici, which started with a minimum of four manic episodes, reaching $88.2 \%$ over 7 years.

\section{Cultural differences in unipolar mania}

There is ample evidence that compared to pure depression (D), pure mania (M) without any minor depressive syndromes (d) is rarer in Western than in non-Western cultures.

Bipolar disorders have been found to have more manic than depressive episodes, for example, among Africans [39]; in Tunisia [40]; in Israel [41]; and among Africans living in England [42]. Similarly, UM is reported as being more frequent in Nigeria [43, 44], Ethiopia [45], South Africa [4], Tunisia [46, 47], India [48] and Hong Kong [49].

Comparing different ethnic groups in Hong Kong, Sing Lee [50] found that 17 of 50 patients attending a lithium clinic had mania only and stressed the higher prevalence of mania in China. A special code for manic disorder was accordingly included in the second edition of the Chinese Classification of Mental Disorders (CCMD-2); the third edition, which integrated ICD-10, retained the diagnosis of recurrent episodic mania [51].

In South Africa, Grobler et al. [3], assisted by an interpreter, studied 94 patients with BP-I disorder, $57 \%$ of whom had previously experienced only manic episodes. $45 \%$ of the group suffered from UM with three or more episodes. When narrower criteria were applied (four or more years' duration of illness and five or more episodes), there still remained a subgroup of 30 of the 94 patients $(32 \%)$ with a recurrent unipolar manic course.

A thorough, comprehensive review of the literature on mania, comprising 17 papers, was provided by Harish et al. [2]. Only three of the studies reviewed were prospective [44, 52, 53]. The NIMH Collaborative Depression Study of Solomon et al. [54] followed up 27 subjects with mania according to the Research Diagnostic Criteria (RDC) over 15-20 years: seven subjects never suffered from major depression and five remained free of any minor depression. The authors concluded that the data support the diagnostic validity of UM.

Despite the scarcity of prospective patient studies, Harish et al. [2] conclude that the sizeable number of patients, reported from several countries and cultures, who demonstrate a recurrent unipolar manic course provides sufficient evidence that the issue of mania's separate status merits further study.

Tables 2 and 3 list clinical studies from Western and non-Western countries, which have investigated UM. The studies are methodologically very diverse, and there are no prospective data from the non-Western studies. Based on retrospective data, the rates of UM were lower in Western than in non-Western countries $(23.1 \%$ vs. $36.8 \%)$. The three prospective studies in Western countries gave even lower rates of $11.0 \%$.

Differences in the clinical characteristics of UM and bipolar disorder

Some studies are inconclusive methodologically, because previous depression is not documented or the observation period is too short, as mentioned by Yazici et al. 2002 [5].

In the latter study, carried out in Turkey, the authors compared 48 patients with UM (defined as mania with at least 4 manic/hypomanic episodes) with 224 patients with bipolar-I disorder. The two groups differed significantly in important respects. The patients with mania were younger 
Table 2 Clinical studies: rates of unipolar mania (UM) in Western countries

\begin{tabular}{|c|c|c|c|c|c|c|c|c|}
\hline Author & Country & Year & $\begin{array}{l}\text { Diagnosis ICD/DSM M } \\
\text { (manic episodes) }\end{array}$ & Minimum $N$ of episodes & Follow-up (years) & $\begin{array}{l}\text { Sample } \\
N\end{array}$ & $\begin{array}{l}\mathrm{UM} \\
N\end{array}$ & $\begin{array}{l}\mathrm{UM} \\
\%\end{array}$ \\
\hline Perris & Sweden & 1966 & Bipolar (I + II) & $1+$ & 0 & 155 & 17 & 11.0 \\
\hline Abrams and Taylor & USA & 1974 & BP-I & $1+$ & 0 & 50 & $14^{\mathrm{a}}$ & 28.0 \\
\hline Abrams et al. & USA & 1979 & BP-I & $2+$ & 0 & 77 & 29 & 37.7 \\
\hline Nurnberger et al. & USA & 1979 & BP-I & $1+$ & 0 & 241 & 38 & 15.7 \\
\hline Pfohl et al. & USA & 1982 & Manic episodes & $1+$ & 0 & 247 & 87 & 35.2 \\
\hline Shulman and Tohen & USA & 1994 & DSM BP-I & $3+$ & $3-10$ & 50 & 6 & 12.0 \\
\hline \multirow[t]{4}{*}{ Solomon et al. } & USA & 2003 & BP-I or schizomania & $1+$ start & 0 & 229 & 27 & 11.8 \\
\hline & & & & & $15-20$ & 229 & 7 & 3.1 \\
\hline & & & BP-I & $1+$ & $15-20$ & 163 & 14 & 8.6 \\
\hline & & & Schizomania & $1+$ & $15-20$ & 66 & 13 & 19.7 \\
\hline Angst et al. & Switzerland & 2004 & DSM BP-I & $1+$ & $22-26$ & 160 & 30 & 15.8 \\
\hline Perugi et al. & Italy & 2007 & $\begin{array}{l}\text { DSM-III-R Mania w/o } \\
\text { MDD/MinDD }\end{array}$ & $3+$ in $10+$ years & 0 & 87 & 19 & 21.8 \\
\hline All studies together & & & & & & 1,525 & 294 & 19.3 \\
\hline Retrospective studies & & & & & & 1,086 & 251 & 23.1 \\
\hline Three prospective studies & & & & & & 439 & 43 & 11.0 \\
\hline
\end{tabular}

Most significant results are in bold

ICD International Classification of Diseases

$D S M$ Diagnostic and Statistical Manual of Mental Disorders

$B P-I$ bipolar-I disorder

$M D D$ major depressive disorder

MinDD minor depressive disorder (dysthymia, minor depression, recurrent brief depression)

a 12 of 14 had $3+$ manic episodes

and had an earlier age at onset, higher rates of psychotic features and hyperthymic temperament than the bipolar group, whereas suicide attempts and rapid cycling were less frequent and fewer patients in the manic group responded to lithium [55].

In a retrospective study on recurrent pure mania carried out at the Fiji Islands' single hospital, patients were selected from all admissions and consultations over a 22-month period from 1999 to 2000 [56]. A diagnosis of UM (ICD10) required at least three previous manic/hypomanic episodes. The patients were interviewed by the PSE (tenth edition), and those with depressive symptoms or syndromes were excluded. No follow-up was carried out. Fifty-one patients with UM, representing $47.2 \%$ of the bipolar affective population during the whole period, were compared to 31 patients with bipolar disorder. This study found no significant differences between the two groups (small Ns) in regard to family history for any major psychiatric morbidity ( $9.8 \%$ vs. $22.6 \%$ ), age at onset (mean 24.2 years vs. 31.2 years $)$ or gender $(M=45.1 \%$ vs. $F=64.5 \%)$, but there were trends in the expected directions (lower in patients with mania). A weaker family history of MDD was found by Ghaffarinejad et al. [57] among patients with mania compared to those with BP-I disorders $(p<0.005)$.
Many studies have reported differences in the psychopathology of UM and bipolar disorder. Several found a trend to higher rates of psychotic symptoms among patients with UM compared to those with BP. In some studies, this trend was not significant on account of the small Ns: Douki et al. [40], Perugi et al. [58], Andrade-Nascimento [59]. In Grobler's study [4], too, the group with UM tended to have more psychotic symptoms compared to the BP group, namely delusions: $89 \%(53 / 59)$ versus $79 \%(35 / 44)$, $p=0.166$; paranoid ideation: $88 \%(52 / 59)$ versus $61 \%$ (27/44), $p=0.002$; and hallucinations: $77 \%(46 / 59)$ versus $63 \%$ (28/44), $p=0.126$. Moreover, some studies report a trend among patients with UM both to increased rates of grandiose delusions: Abrams et al. [60], Kirov and Murray [42], Pfohl et al. [61] and to mood-incongruent psychotic symptoms [7, 57].

Treatment studies

Two studies reported the effects of lithium prophylaxis on UM. Whereas Nurnberger et al. [62] could not find clear differences between UM $(N=20)$ and BP-I $(N=88)$, Yazici and Çakir [7] found that patients with UM responded less well than patients with BP-I to lithium $(13 / 24=54 \%$ 
Table 3 Clinical studies rates of unipolar mania (UM) in non-Western countries

\begin{tabular}{|c|c|c|c|c|c|c|c|c|}
\hline Author & Country & Year & $\begin{array}{l}\text { Diagnosis Bipolar disorder with } \mathrm{M} \\
\text { (manic episodes) }\end{array}$ & Minimum $N$ episodes & $\begin{array}{l}\text { Prospective } \\
\text { (years) }\end{array}$ & $\begin{array}{l}\text { Sample } \\
N\end{array}$ & $\begin{array}{l}\mathrm{UM} \\
N\end{array}$ & $\begin{array}{l}\mathrm{UM} \\
\%\end{array}$ \\
\hline Srinivasan et al. & India & 1985 & DSM-III & $3+$ & 0 & 29 & 12 & 42 \\
\hline Makanjuola & Nigeria & 1985 & Manic episodes & $1+$ & $\begin{array}{l}3 \text { months- } \\
5 \text { years }\end{array}$ & 104 & $55^{\mathrm{a}}$ & 52.6 \\
\hline Margoob and Dutta & India & 1988 & MDP & $1+$ & 0 & 43 & 21 & 49 \\
\hline Khanna et al. & India & 1992 & RDC & $2+^{\mathrm{b}}$ & 0 & 70 & 42 & 60 \\
\hline Aghanwa & Fiji Islands & 2001 & ICD-10 & $3+$ & 0 & 108 & 51 & 47.2 \\
\hline Yazici et al. & Turkey & 2002 & DSM-IV BP-I & $4+$ & 0 & 272 & 48 & 16.3 \\
\hline Negash et al. & Ethiopia & 2005 & DSM-IV, ICD-10 & & 0 & 295 & 176 & 59.8 \\
\hline Benzineb et al. & Tunisia & 2005 & DSM-IV BP-I & & 0 & 129 & 46 & 35.7 \\
\hline Dakhlaoui et al. & Tunisia & 2008 & DSM-IV BP-I & $2+$ & 0 & 72 & 47 & 65.3 \\
\hline Andrade-Nascimento et al. & Brazil & 2011 & DSM-IV & $1+$ & 0 & 298 & 16 & 5.4 \\
\hline Thirthalli et al. & India & 2011 & BP admissions & $1+$ & 0 & 315 & 148 & 47.0 \\
\hline Ghaffarinejad et al. & Iran & 2013 & DSM BP-I & $1+$ & 0 & 219 & 49 & 22.4 \\
\hline \multirow[t]{2}{*}{ Grobler et al. } & South Africa & 2014 & DSM-IV & $3+$ & 0 & $94 *$ & 42 & 44.7 \\
\hline & & & & $5+$ & 0 & 94 & 30 & 31.9 \\
\hline All studies together & & & & & & 2,048 & 753 & 36.8 \\
\hline Retrospective & & & & & & 1,964 & 698 & 35.9 \\
\hline One prospective & & & & & & 104 & 55 & 52.6 \\
\hline
\end{tabular}

* Not included in the sum of studies

DSM Diagnostic and Statistical Manual of Mental Disorders

$M D P$ major depressive psychosis

$R D C$ Research Diagnostic Criteria

ICD International Classification of Diseases

$B P-I$ bipolar-I disorder

a Another 36 patients had a single manic episode [twice as many men (24) as women (12)]

b 15 of $70(21.4 \%)$ had $4+$ episodes

vs. $63 / 76=83 \%, p<0.004)$, and there was no difference in their response to valproate.

Grobler [3] found that patients with UM tended to be prescribed more antipsychotics than BP-I patients: for example, haloperidol: $54 \%(32 / 59)$ versus $43 \%(19 / 44), p=0.321$; zuclopenthixol depot: $49 \%(29 / 59)$ versus $38 \%$ (17/44), $p=0.321$; and risperidone: $23 \%(14 / 59)$ versus $20 \%$ (9/44), $p=0.812$, but not significantly more mood stabilisers: lithium: $18 \%(11 / 59)$ versus $25 \%(11 / 44), p=0.473$ and valproate: $57 \%(34 / 59)$ versus $59 \%(26 / 44, p=1.000$.)

\section{Cardiovascular studies}

Among individuals with bipolar disorder, the mortality rates for cardiovascular conditions are double those expected from general population estimates; the manic symptom burden was also found to be predictive [63]. Vasculopathy was found to be related to the manic/hypomanic symptom burden [64], and accelerated vascular ageing (vascular stiffness) was reported in patients with bipolar disorder [65].
In a recent 50-year follow-up of 403 hospital admissions, we found that cardiovascular mortality rates increased systematically across the affective spectrum, from MDD via BP-II and BP-I disorder to mania (M, Md), with the following standardised mortality ratios (SMRs): 1.32, 1.60(*), 1.99**, 3.17* [33]. As suggested in the latter study, the threefold cardiovascular mortality in patients with UM may be a consequence of the increased stress burden of the manic component, expressed in excessive activity, short sleep, lifestyle, secondary substance abuse, etc.

Twin and family studies

The twin study of McGuffin et al. [66] comprising 30 monozygotic and 37 dizygotic twin pairs in which the proband had bipolar disorder convincingly demonstrated a heritability of $0.85-0.89$ of bipolar disorder but also showed a substantial genetic correlation between mania and depression (0.65) and a large correlation (0.59) for environmental effects not shared within families. 
In a very recent US (NIMH) family study, Merikangas et al. [67] investigated 290 subjects with mood disorders (62 BP-I, 66 BP-II and 162 MDD), 157 controls and 2,082 living and deceased first-degree relatives. The authors found specific familial aggregations of probands' mania with relatives' mania [OR $\left.=8.3(3.8-17.9)^{* *}\right]$ with a heritability of 0.83 and a much lower association of probands' major depression with relatives' major depression $\left[\mathrm{OR}=2.5(1.7-3.6)^{* *}\right.$. No significant transmission from mania to major depression or vice versa was found, and no significant transmission was found for hypomania, nor was the latter associated with mania or major depression. Compatible results were reported simultaneously from a Swiss (Lausanne) family study by Vandeleur et al. [68], who investigated patients with schizo-affective disorders $(N=62)$, BP-I disorder $(N=100)$, BP-II disorder $(N=23)$ and $\operatorname{MDD}(N=108), 110$ orthopaedic controls and 1,734 first-degree relatives. The familial aggregation for manic episodes [OR $=6.4(2.2-18.7)]$ was markedly higher than for MDE [OR 2.0 (1.7-2.7)]; hypomania again showed no significant aggregation.

Commenting on the latter two studies, Hickie stressed the link between psychotic syndromes and mania found by Vandeleur et al. [69] in the Lausanne study and the genetic independence of mania from depression reported in both the NIMH and Lausanne studies. He proposed a new concept for mood disorders, consisting of three dimensions: (1) increased activation as a core feature of mania and decreased activation as characteristic of some but not all depression, (2) depression and (3) psychosis. This proposal is reminiscent of the model of Carl Wernicke referred to in the introduction.

One molecular genetic study found some associations with six cases of UM; the study is too small, however, to be conclusive [70].

\section{Discussion}

There is clear evidence of the heterogeneity of bipolarI disorder [71]. Although UM, defined as pure mania (M) and mania with $\mathrm{Md}$, is rather rare compared to major depressive disorder and bipolar disorder, this is no reason for neglect. Mania has been convincingly shown to exist in adults by the EDSP prospective epidemiological study (Munich) and in adolescents by the cross-sectional NCS-A study (USA) [35]. In the former, the rates were as follows: $M=0.6 \%$ and $\mathrm{Md}=0.9 \%$; in the latter (with no follow-up), the rate was $1.7 \%$ for mania without MDE. Hypomania without MDE (m, md) was diagnosed in $1.5 \%$ of subjects in the Munich EDSP study. These rates may of course diminish over lifetime, because of the subjects being relatively young (up to age 34 ) and the infrequency of late-onset mania [72]. The diagnostic stability of mania over a prospective follow-up of 10 years was found to be high with $75 \%$ in a very sound Chinese study and by other follow-up studies based on retrospective data (Table 3 ).

Clinical studies on UM are relatively scarce, the samples usually small and the results less conclusive than those of epidemiological investigations. More especially, there is a dearth of prospective clinical studies on the course of UM. Nevertheless, there is converging evidence from patient studies that UM and bipolar disorder differ. On the one hand, patients with UM have a weaker family history, especially for MDD, an earlier onset of the disorder, better remission with fewer recurrences, and experience fewer comorbid anxiety disorders. On the other, they more often manifest psychotic symptoms, are more frequently treated with antipsychotics and probably respond less well to lithium prophylaxis. In temperament, they are predominantly hyperthymic or hypomanic. In addition, cardiovascular mortality, already higher in BP disorders than in MDD, was found to be highest in patients with UM.

The lower rates of UM in Western countries, mentioned in the reviews, are confirmed (Tables 2, 3). This consistent finding is difficult to interpret: cultural differences in the expression of affect, in the social acceptability of depression and mania, in treatment seeking and in the availability of treatment may all play a role.

Finally, the family and twin studies showing that mania is much more heritable than depression provide strong arguments in favour of keeping manic episodes and UM as distinct concepts for further research.

All available reviews of the literature on UM reach similar conclusions. We need to question the traditional concept of the unipolar-bipolar dichotomy. As Cuellar et al. [73] argue in their large overview of research on bipolar and unipolar depression, we need to "study mania and depression as separate disorders, rather than as bipolar and unipolar disorders, so enabling the field to tease apart processes that are similar and unique between these phenomena that with the current nomenclature is not probable". A similar view was expressed by Young et al. [36] and fully concords with the recent reviews of the literature on UM cited in the introduction $[2,3,7,8]$.

How could this translate in practice? For the diagnosis of a manic episode, criterion A would be broader than in DSM-5, i.e. increased activity/energy $\underline{\text { or }}$ elated/expansive mood or irritable mood (pace DSM-5, increased activity/ energy is not required in all cases). Criteria B (number of symptoms) and $\mathrm{C}$ [consequences (social or work impairment, hospitalisation) or psychotic features] would correspond to DSM-5, whereas criterion D (exclusion criteria) should be omitted. If during their lifetime a person had experienced only manic episodes and never MDE, the diagnosis would be manic disorder (M); if they had also 
experienced a minor depressive disorder, dysthymia or recurrent brief depression, the diagnosis would be mania with minor depressive disorder (Md).

\section{Conclusions}

Although relatively rare, UM and unipolar hypomania exist, and both can co-occur with minor depressive disorders. Unipolar is not bipolar; if we accept that unipolar depression is distinct from bipolar disorder, it is illogical not to think that UM may also be so. A simple unipolar/ bipolar dichotomy is outdated and should be replaced by a spectrum of major mood disorders, distinguishing clearly between five subgroups, extending from depression via bipolar-II and bipolar-I disorders to mania with minor depression and pure mania without depression: D-Dm-MD-Md-M.

Further prospective clinical, transcultural, genetic and brain research is certainly needed for progress in the field; studies should routinely distinguish between mania, bipolar disorder and depressive disorder. Such an approach would be strongly encouraged by the introduction of manic episodes or, better still, UM as coded diagnoses in ICD and DSM. This would be preferable to the addition of a course specifier for UM to the diagnosis of bipolar disorder, as recommended by Grobler et al. [3], Yazici [6], Mehta [8], since this continues to anchor UM within bipolar disorder.

A special code for mania would also help to clarify cultural differences in the expression of the severity and symptomatology of mania and in treatment and placebo response rates [74].

Conflict of Interest On behalf of all authors, the corresponding author states that there is no conflict of interest.

\section{References}

1. American Psychiatric Association (2013) Diagnostic and statistical manual of mental disorders DSM-5 ${ }^{\mathrm{TM}}$, 5th edn. American Psychiatric Association, Arlington

2. Harish T, Grover S, Basu D (2005) Recurrent unipolar mania: does it warrant a separate nosological status? Ger J Psychiatry $8: 8-15$

3. Grobler C, Roos JL, Bekker P (2014) Unipolar mania reconsidered evidence from a South African study. Afr J Psychiatry 17:473-491

4. Grobler C (2012) A cross-sectional descriptive study of clinical features and course of illness in a South African population with bipolar disorder. University of Pretoriy, Pretoria

5. Yazici O, Kora K, Ücok A, Saylan M, Özdemir Ö, Kiziltan E, Özpulat T (2002) Unipolar mania: a distinct disorder? J Affect Disord 71:97-103

6. Yazici O (2014) Unipolar mania: a distinct entity? J Affect Disord 152-154:52-56
7. Yazici O, Cakir S (2012) Unipolar mania: a distinct entity or characteristic of manic preponderance? Turk Psikiyatri Derg 23:201-205

8. Mehta S (2014) Unipolar mania: recent updates and review of the literature. Psychiatry J 2014:209-213. doi:10.1155/2014/261943

9. Angst J, Marneros A (2001) Bipolarity from ancient to modern times: conception, birth and rebirth. J Affect Disord 67:3-19

10. Porter R (1995) Mood disorders. Social section. In: Berrios G, Porter R (eds) A history of clinical psychiatry. The origin and history of psychiatric disorders. Athlone, London, pp 409-420

11. Healy D (2008) Mania: a short history of bipolar disorder. Johns Hopkins University Press, Baltimore

12. Falret JP (1851) De la folie circulaire ou forme de maladie mentale caractérisée par l'alternative régulière de la manie et de la mélancholie. Bull Acad Med 24:18-19

13. Baillarger J (1854) De la folie à double forme. Ann Med Psychol 6:369-384

14. Kraepelin E (1899) Psychiatrie. Ein Lehrbuch für Studierende und Aerzte., vol II Klinische Psychiatrie. 6. vollständig umgearbeitete Ausgabe edn. Verlag Johann Ambrosius Barth, Leipzig

15. Wernicke C (1896) Grundriss der Psychiatrie in klinischen Vorlesungen. Georg Thieme, Leipzig

16. Kleist K (1911) Die Streitfrage der akuten Paranoia. Ein Beitrag zur Kritik des manisch-depressiven Irreseins. Z Ges Neurol Psychiatrie 5:366-387

17. Kleist K (1928) Über zykloide, paranoide und epileptoide Psychosen und über die Frage der degenerationspsychosen. Schweiz Arch Neurol Neurochir Psychiatry 23:3-37

18. Leonhard K (1948) Grundlagen der psychiatrie. Enke, Stuttgart

19. Neele E (1949) Die phasischen Psychosen nach ihrem Erscheinungs- und Erbbild. Johann Ambrosius Barth Verlag, Leipzig

20. Angst J (1966) Zur Ätiologie und Nosologie endogener depressiver Psychosen. Eine genetische, soziologische und klinische Studie. Springer, Berlin Heidelberg New York

21. Perris C (1966) A study of bipolar (manic-depressive) and unipolar recurrent depressive psychoses. Acta Psychiatry Scand 42:1-189

22. Winokur G, Clayton PJ, Reich T (1969) Manic depressive illness. C.V. Mosby Company, Saint Louis

23. Dunner DL, Gershon ES, Goodwin FK (1976) Heritable factors in the severity of affective illness. Biol Psychiatry 11:31-42

24. Akiskal HS (1983) The bipolar spectrum: new concepts in classification and diagnosis. In: Grinspoon L (ed) Psychiatry update: the American Psychiatric Association Annual Review, vol II. American Psychiatric Press, Washington, pp 271-292

25. Angst J (2007) The bipolar spectrum. Br J Psychiatry 190:189-191

26. Angst J, Gamma A (2002) Prevalence of bipolar disorders: traditional and novel approaches. Clin Appr Bipol Disord 1:10-14

27. Kretschmer E (1921) Körperbau und Charakter. Untersuchungen zum Konstitutionsproblem und zur Lehre von den Temperamenten, vol 1. Springer, Berlin

28. Tellenbach R (1974) Untersuchungen zur prämorbiden Persönlichkeit von Psychotikern. Technische Universität München, München

29. Tellenbach R (1975) Typologische Untersuchungen zur prämorbiden Persönlichkeit von Psychotikern unter besonderer Berücksichtigung Manisch-Depressiver. Confinia Psychiatry 18:1-15

30. von Zerssen D (1977) Premorbid personality and affective psychoses. In: Burrows GD (ed) Handbook of studies on depression. Excerpta Medica, Amsterdam London, New York, pp 79-103

31. von Zerssen D (1996) 'Melancholic' and 'manic' types of personality as premorbid structures in affective disorders. In: Mundt C, Goldstein MJ, Hahlweg K, Fiedler P (eds) Interpersonal factors in the origin and course of affective disorders. Gaskell, London, pp 65-85 
32. Angst J (2013) The spectra of major and minor mood disorders. CEPiP 1:10-15

33. Angst J, Hengartner MP, Gamma A, von Zerssen D, Angst F (2013) Mortality of 403 patients with mood disorders 48 to 52 years after their psychiatric hospitalisation. Eur Arch Psychiatry Clin Neurosci 263:425-434

34. Beesdo K, Hofler M, Leibenluft E, Lieb R, Bauer M, Pfennig A (2009) Mood episodes and mood disorders: patterns of incidence and conversion in the first three decades of life. Bipolar Disord 11:637-649

35. Merikangas KR, Cui L, Kattan G, Carlson G, Youngstrom EA, Angst J (2012) Mania with and without depression in a community sample of U.S. adolescents. Arch Gen Psychiatry 69:943-951

36. Young AH, Marek S, Patterson RM (2009) Unipolar mania. In: Figueira ML, Akiskal H (eds) Clinical aspects of mania. Wolters Kluwer Health, Alphen aan den Rijn, pp 39-45

37. Pacheco Palha A, Arrojo A (2009) Clinical aspects of unipolar mania. In: Figueira ML, Akiskal H (eds) Clinical aspects of mania. Wolters Kluwer Health, Alphen aan den Rijn, pp 47-52

38. Xu WY, Chen ZJ (1992) An eight- to ten-year outcome study of unipolar mania (in Chinese). Shanghai Arch Psychiatry 4:88-90

39. Diop M (1967) La dépression chez le noir africain. Psychopathol Afr 3:183-194

40. Douki S, Ben Zineb S, Nacef F, Choubani Z (2007) Aspectos culturales de los trastornos afectivos. In: Moussaoui D, Casas M (eds) Salud mental en el paciente Magrebí. Editorial Glosa S.L, Barcelona, pp 177-193

41. Osher Y, Yaroslavsky Y, El-Rom R, Belmaker RH (2000) Predominant polarity of bipolar patients in Israel. World J Biol Psychiatry 1:187-189

42. Kirov G, Murray RM (1999) Ethnic differences in the presentation of bipolar affective disorder. Eur Psychiatry 14:199-204

43. Makanjuola RO (1982) Manic disorder in Nigeria. Br J Psychiatry 141:459-463

44. Makanjuola RO (1985) Recurrent unipolar manic disorder in the Yoruba Nigerian: further evidence. Br J Psychiatry 147:434-437

45. Negash A, Alem A, Kebede D, Deyessa N, Shibre T, Kullgren G (2005) Prevalence and clinical characteristics of bipolar I disorder in Butajira, Ethiopia: a community-based study. J Affect Disord 87:193-201

46. Dakhlaoui O, Essafi I, Haffani F (2008) Particularisme clinique du trouble bipolaire: la manie unipolaire. À propos d'une étude de patients en Tunisie. Encephale 34:337-342

47. BenZineb S, Douki S (2000) La manie unipolaire. In: XII Journée Tunisienne de Psychiatrie, Tunis (poster)

48. Khanna R, Gupta N, Shanker S (1992) Course of bipolar disorder in eastern India. J Affect Disord 24:35-41

49. Lee S (1992) The first lithium clinic in Hong Kong: a Chinese profile. Aust N Z J Psychiatry 26:450-453

50. Lee S, Yu H (1994) Unipolar mania in non-Western cultures. Br J Psychiatry 165:413

51. Chen YF (2002) Chinese classification of mental disorders (CCMD-3): towards integration in international classification. Psychopathology 35:171-175

52. Shulman KI, Tohen M (1994) Unipolar mania reconsidered: evidence from an elderly cohort. Br J Psychiatry 164:547-549

53. Solomon DA, Leon AC, Endicott J, Coryell W, Mueller TI, Posternak MA, Keller MB (2003) Unipolar mania over the course of a 20-year follow-up study. Am J Psychiatry 160:2049-2051

54. Spitzer RL, Endicott J, Robins E (1978) Research diagnostic criteria: rationale and reliability. Arch Gen Psychiatry 35:773-782

55. Yazici O, Cakir S, Kora K (2008) Validity of unipolar mania diagnosis (abstract). In: Chengappa KNR, Gershon S (eds) 3rd Biennial Conference of the International society for Bipolar
Disorders. Delhi, India, January 27-28 2008, Agra, India, January 30 2008, 2008. Bipolar Disord, p 66

56. Aghanwa HS (2001) Recurrent unipolar mania in a psychiatric hospital setting in the Fiji Islands. Psychopathology 34:312-317

57. Ghaffarinejad A, Mehdizadeh Zare Anari A, Mirghiasi (2013) A Prevalence of unipolar mania and evaluation of the characteristics in unipolar and bipolar mania in Kerman (Iran). In: 21th European congress of psychiatry, 6-9 April, 2013, Nice

58. Perugi G, Sanna Passino MC, Toni C, Maremmani I, Angst J (2007) Is unipolar mania a distinct subtype? Compr Psychiatry 48:213-217

59. Andrade-Nascimento M, Miranda-Scippa A, Nery-Fernandes F, Kapczinski F, Quarantini L (2011) The identification of unipolar mania subtype based on anxiety comorbidity. J Affect Disord 132:356-359

60. Abrams R, Taylor MA, Hayman MA, Krishna NR (1979) Unipolar mania revisited. J Affect Disord 1:59-68

61. Pfohl B, Vasquez N, Nasrallah H (1982) Unipolar vs. bipolar mania: a review of 247 patients. Br J Psychiatry 141:453-458

62. Nurnberger JI, Roose SP, Dunner DL, Fieve RR (1979) Unipolar mania: a distinct clinical entity? Am J Psychiatry 136:1420-1423

63. Murray DP, Weiner M, Prabhakar M, Fiedorowicz JG (2009) Mania and mortality: why the excess cardiovascular risk in bipolar disorder? Curr Psychiatry Rep 11:475-480

64. Fiedorowicz JG, Coryell WH, Rice JP, Warren LL, Haynes WG (2012) Vasculopathy related to manic/hypomanic symptom burden and first-generation antipsychotics in a sub-sample from the collaborative depression study. Psychother Psychosom 81:235-243

65. Sodhi SK, Linder J, Chenard CA, Miller DD, Haynes WG, Fiedorowicz JG (2012) Evidence for accelerated vascular aging in bipolar disorder. J Psychosom Res 73:175-179

66. McGuffin P, Rijsdijk F, Andrew M, Sham P, Katz R, Cardno A (2003) The heritability of bipolar affective disorder and the genetic relationship to unipolar depression. Arch Gen Psychiatry 60:497-502

67. Merikangas KR, Cui L, Heaton L, Nakamura E, Roca C, Ding J, Qin H, Guo W, Yao-Shugart Y, Zarate C, Angst J (2014) Independence of familial transmission of mania and depression: results of the NIMH family study of affective spectrum disorders. Mol Psychiatry 19:214-219

68. Vandeleur CL, Merikangas KR, Strippoli MP, Castelao E, Preisig M (2014) Specificity of psychosis, mania and major depression in a contemporary family study. Mol Psychiatry 19:209-213

69. Hickie IB (2014) Independence of mania and depression. Evidence for separate inheritance of mania and depression challenges current concepts of bipolar mood disorder. Mol Psychiatry 19:153-155

70. Chiaroni P, Azorin JM, Dassa D, Henry JM, Giudicelli S, Malthiéry Y, Planells R (2000) Possible involvement of the dopamine D3 receptor locus in subtypes of bipolar affective disorder. Psychiatry Genet 10:43-49

71. Angst J, Gerber-Werder R, Zuberbühler H-U, Gamma A (2004) Is bipolar I disorder heterogeneous? Eur Arch Psychiatry Clin Neurosci 254:82-91

72. Venkoba Rao A, Madhavan T (1983) Depression and suicide behavior in the aged. Indian J Psychiatry 25:251-259

73. Cuellar AK, Johnson SL, Winters R (2005) Distinction between bipolar and unipolar depression. Clin Psychol Rev 25:307-339

74. Vieta E, Pappadopulos E, Mandel FS, Lombardo I (2011) Impact of geographical and cultural factors on clinical trials in acute mania: lessons from a ziprasidone and haloperidol placebo-controlled study. Int J Neuropsychopharmacol 14:1017-1027 